\title{
As Remodelagens Institucionais nas Estruturas de Apoio à Promoção Comercial no Brasil
}

\author{
Ariane Figueira ${ }^{1}$ \\ ${ }^{1}$ Instituto de Pós-Graduação e Pesquisa em Administração (COPPEAD) da Universidade Federal do Rio \\ de Janeiro (UFRJ). Rio de Janeiro, RJ. Brasil. \\ E-mail: ariane.roder@coppead.ufrj.br, http:/ /orcid.org/0000-0002-2900-3040
}

\section{INTRODUÇÃO}

$\mathrm{O}$ papel que o Estado deve desempenhar na economia é um debate antigo que, ao longo da história, tem dividido a opinião de intelectuais que se posicionam entre um extremo e outro, isto é, ora em defesa do livre mercado, ora apontando para a importância da intervenção e regulação do mercado pelas estruturas estatais. Essa divisão de posicionamento também tem tangenciado a trajetória dos países, ditando de algum modo o rumo da história global, tendo demonstrado que, empiricamente, nenhum dos modelos teóricos é capaz de responder sozinho e adequadamente a realidades cada vez mais complexas e difusas.

Em tempos recentes, experimentou-se um avanço no processo de liberalização econômica, acelerada pelos efeitos provocados pelo desenvolvimento tecnológico, nos transportes, nas comunicações, tornando o fluxo de pessoas e mercadorias mais intensos e as economias mais interdependentes (Keohane; Nye, 1998). Nesse contexto, revigorou-se o debate em torno do escopo de atuação do Estado em um cenário de perda relativa de poder frente às fronteiras cada vez mais permeáveis. David Held (1991:158) dá destaque a esse processo.

No contexto de uma ordem global altamente interconectada, muitas atividades e responsabilidades tradicionais do Estado (como a defesa, a administração da economia, as comunicações, os sistemas administrativos e legais) não podem ser realizadas ou assumidas sem o concurso da colaboração internacional. À medida que as demandas apresentadas ao poder público cresceram nos anos de pós-guerra, o Estado viu-se

DADOS, Rio de Janeiro, vol.62(1):e20190019, 2019. 
confrontado, cada vez mais, com problemas políticos que não podem ser resolvidos sem a cooperação de outros atores estatais e não estatais.

Contudo, vale destacar que, a despeito das adaptações necessárias de qualquer agente em um cenário em constante mutação, o Estado ainda exerce papel importante na sociedade e na economia, já que se trata do ambiente territorial, regulatório e institucional em que as empresas operam, podendo sofrer diferentes efeitos advindos do seu país de origem, como também do país hospedeiro (Dicken, 2007). Assim, as ações do Estado podem ter efeitos de incentivos ou constrangimentos a determinados movimentos corporativos, ou seja, de modo geral, suas ações podem afetar direta ou indiretamente a decisão do empreendedor. $\mathrm{O}$ autor sumariza algumas dessas ações que são ferramentas que podem ser usadas pelos governos para exercerem influência nas decisões de mercado, tais como:

(...) incentivos financeiros e fiscais; garantias de créditos à exportação; definição de metas de exportação; operações de agências de promoção à exportação; estabelecimento de zonas de exportação ou de livre comércio; restrições voluntárias à exportação; embargos às exportações estratégicas; manipulação cambial etc (Dicken, 2007:81).

Por outro lado, não apenas o Estado exerce grande influência sobre o planejamento das empresas. Stopford e Strange (1991), em Rival States and Rival Firms: Competition for World Market Shares, destacam a crescente interdependência entre as empresas e os Estados no contexto contemporâneo, sendo eles agentes importantes no triângulo diplomático proposto pelo modelo. Além disso, o texto aponta para o fato de os Estados também estarem cada vez mais dependentes do capital global movimentado pelas multinacionais, o que tem levado ao diálogo mais estreito com o setor privado.

Diante disso, a proposta deste artigo é compreender como o Estado brasileiro tem respondido historicamente a essas transformações sistêmicas, buscando analisar, particularmente, as remodelagens ocorridas na área de promoção e suporte ao comércio exterior, com foco direcionado para a constituição de arranjos institucionais e decisórios e de canais oficiais de diálogo entre agentes empresariais e instituições governamentais. 
Assim, este artigo pretende contribuir para preencher um espaço do conhecimento ainda pouco explorado pela academia, que tem apostado prioritariamente em estudar os outputs da política externa brasileira, deixando vácuos interpretativos sobre as transformações histórico-institucionais que vêm ocorrendo na administração pública direta, no âmbito federal, com objetivo de responder a demandas cada vez mais complexas e transversais. Outro ponto de relevância do tema são os aspectos da interação e diálogo entre empresas e governo que ganham novos contornos nesse contexto. Dessa forma, algumas questões irão permear o artigo em formato longitudinal e complementar, sendo elas: Quais são as demandas na área comercial brasileira? Existem canais de diálogo para captação desses anseios? Quais as instituições de apoio? Como se estrutura o diálogo entre elas? Como os rearranjos institucionais ocorridos ao longo das últimas décadas têm impactado o processo de negociação e o conteúdo das políticas?

Para elucidar os processos envolvendo as questões supracitadas o artigo está dividido em quatro seções. Na primeira, o objetivo é explorar, dentro do contexto de políticas comerciais majoritariamente protecionistas que caracterizaram a segunda metade do século $X X$ no Brasil, o formato de organização institucional de promoção comercial do país nesse período e as reestruturações derivadas de demandas domésticas e internacionais impulsionadas pelo novo ambiente de negócios que se desenhou a partir de então. Na segunda, a narrativa envolveu um momento de total reestruturação da área no Brasil, com a fragilização de antigas instituições, fragmentação decisória e, posteriormente, com a estruturação de uma gestão e responsabilidades compartilhadas de diversos ministérios, além do crescente envolvimento da classe empresarial brasileira. Na terceira seção, buscou-se apresentar o duplo movimento de consolidação da área, ou seja, com indicadores do comércio exterior sendo alavancados, demonstrando-se relevantes para o desenvolvimento do país e, também, com ajustes no escopo de competência de algumas agências, no sentido de dar dinamicidade, publicidade, irradiar as ações através de novas tecnologias, assim como apostar em políticas voltadas para atração e emissão de Investimento Direto Externo. Foi nesse contexto que se objetivou reforçar a presença brasileira no exterior, seja com um estreitamento dos laços diplomáticos comerciais com outros países, seja com as empresas brasileiras, aumentando o grau de comprometimento com o mercado externo. Assim também, nessa fase ganhou 
destaque a reestruturação ocorrida nas linhas de financiamento do Banco Nacional de Desenvolvimento Econômico e Social (BNDES), o que viabilizou a "saída" mais assertiva de algumas empresas para competir no mercado internacional. Por fim, na quarta seção, buscou-se amarrar os dados históricos apresentados nas seções anteriores, utilizando-se do referencial teórico para elucidar o papel que o Estado vem desempenhando na área de promoção comercial no contexto de acirrada concorrência internacional.

\section{REFERENCIAL TEÓRICO}

No passado recente, que remonta à década de 1970, a produção do conhecimento científico na área de política externa esteve fortemente concentrada em estudos estratégicos de segurança e defesa. Isto porque, as dinâmicas interestatais eram predominantes até esse período, sendo que questões como guerra e paz mobilizavam centralmente a agenda externa dos Estados. No caso brasileiro, além dessas temáticas também serem focais no entendimento sobre a realidade do país e sua atuação internacional, a análise de produção de políticas nesse período debruçava-se prioritariamente no entendimento sobre o desenho e as características institucionais do Itamaraty, que preservava uma administração centralizada, coesa e insulada em relação às demandas da sociedade.

Essa peculiaridade institucional na produção da política externa levou muitos analistas brasileiros a focar seus estudos nas peculiaridades desse corpo diplomático e como isso afetava diretamente os resultados da política. Alguns estudos ganham destaque nesse período, como o de Zairo Cheibub, em Diplomacia e Construção Institucional: O Itamaraty em uma Perspectiva Histórica, em que busca compreender o histórico de formação do corpo diplomático brasileiro e da estrutura do Ministério em articulação com os distintos momentos do processo de construção do Estado. A finalidade do autor é entender como esse histórico de mudanças e consolidações institucionais que marcaram a trajetória do Itamaraty impactaram "na configuração da arena de formulação e implementação da política externa brasileira" (Cheibub, 1985:133). Sua reconstrução do histórico institucional é realizada mediante as divisões temporais em três distintos momentos, sendo o primeiro definido pelo autor como patrimonial e diplomacia imperial (de 1822 ao final do século XIX); o segundo caracterizado como carismático do Barão de Rio Branco (os anos iniciais do século 
XX), e o terceiro como burocrático/racional (do final da década de 1910 até os dias de hoje). A partir desse estudo, o autor empreende uma das primeiras e principais análises acerca da peculiar história que marca a trajetória do Ministério das Relações Exteriores, sendo hoje observada como um dos elementos centrais para compreensão dos derivativos gerados por essa trajetória na própria dinâmica decisória em assuntos relativos à política externa brasileira.

Recentemente, porém, um crescente número de intelectuais tem se dedicado a compreender os "novos" temas que ganharam força na agenda externa dos Estados, bem como sobre as estruturas que passaram a dialogar de forma mais assertiva com os agentes diplomáticos, tais como: o Congresso, outros ministérios, atores não estatais etc. Lima e Santos, uns dos estudiosos que iniciaram esse debate no Brasil, ressaltam que:

A globalização, no sentido amplo da internacionalização da economia e de diversos fenômenos sociais, fomenta a separação do interno/externo e consequentemente, a internacionalização da agenda doméstica, com a incorporação na esfera de decisão legislativa de questões de política externa, questões que previamente estavam restritas ao Executivo. A integração à economia internacional e a abertura econômica contribuem para a polarização da política externa, tendo em vista os impactos distributivos internos da maior participação no comércio internacional, uma vez que, em uma economia aberta, há ganhos e perdas diferenciadas, frutos de decisões e negociações internacionais (Lima e Santos, 2001:287).

Mais recentemente, nessa mesma direção argumentativa, em busca de estabelecer um diálogo entre as concepções sobre política externa e políticas públicas, Pinheiro e Milani apontam que:

A simultaneidade de fatores - tais como o fim da competição bipolar, a diversificação das coalizões, os processos de globalização e liberalização econômica, as crises financeiras de natureza sistêmica, a revolução tecnológica na área de informação e a ação transnacional de redes de ativismo e movimentos sociais - produziu uma inflexão nas concepções contemporâneas sobre o papel do Estado e em suas práticas no campo da política externa. Surgiram novas possibilidades de ação internacional dos Estados, mas também novos constrangimentos.

Essas e outras interpretações que se fundamentam em premissas mais ampliadas sobre política externa tiveram como origem estudos que for- 
mataram a criação de uma subárea de pesquisa no campo interpretativo das Relações Internacionais, ficando conhecida como Foreign Policy Analysis. Destacam-se nesse processo os trabalhos de: James Rosenau (1966), com Pre-Theories and Theories of Foreign Policy; de Snyder, Bruck e Sapin (1954), Decision Making as an Approach to the Study of International Politics; de Harold e Margaret Sprout (1956), com Main-Milieu Relationship Hypotheses in the Context of International Politics; e ainda o livro de Harold Hance Sprout (1965), The Ecological Perspective on Human Affairs with Special Reference to International Politics.

A obra mencionada de Rosenau influenciou o surgimento de uma tradição teórica dentro dessa subárea: a Política Externa Comparada. Com forte influência behavorista, sua marca é a busca pela identificação de tendências centrais nos padrões de comportamento externo e na diferenciação das escolhas dos Estados, adotando como base variáveis como: nível de desenvolvimento econômico do país, processos históricos, características institucionais, tipo de sociedade, estruturas de governo, sistema internacional, entre outras, perpassando por diferenciados níveis de análise. Essa tradição teórica foi posteriormente criticada pela excessiva quantificação de uma realidade complexa que envolve dinâmicas que não podem ser aferidas pela matemática e pela estatística, tais como: percepção dos agentes, emoções, cultura, história, além de não atribuir significativa importância à interrelação dinâmica dos ambientes doméstico e internacional, bem como para a participação de atores não estatais nesses processos (Jesus, 2014).

Portanto, em virtude das deficiências atribuídas à tradição da Política Externa Comparada - que durante algum tempo foi responsável por uma extensa agenda de pesquisa - a Segunda Geração de Análise de Política Externa visa romper com essas estritas parametrizações matemáticas e com a positivação extremada dos comportamentos e das preferências estatais que caracterizaram a geração anterior. A proposta se propõe a criar ferramentas de análise que possam abarcar a multifatorialidade, a interdisciplinaridade, a compreensão dos elementos centrais e as correlações entre determinantes internos e externos, a utilização de metodologias quantitativas e qualitativas, além da categorização dos grupos em diferentes dimensões e níveis de análise (Carlsnaes; Guzzini, 2011). A obra de Snyder, Bruke e Sapen (1954) marca essa tradição analítica do Processo Decisório da Política Externa, sendo que os pensadores que se debruçaram sobre essa temática utilizaram como atores específicos ou variáveis centrais diferentes 
fatores, tais como: o indivíduo, as burocracias, os grupos de interesse, a interação dos poderes Legislativo e Executivo, as instituições políticas, as regras decisórias, ou seja, cada grupo de pesquisadores se preocupou em examinar um desses elementos (Hudson ; Vore, 1995). Essa geração destaca que, mais importante e prioritária para compreender os outputs (ou seja, as decisões e ações de política externa dos Estados), é a necessidade de entender o dinâmico processo com múltiplos atores e níveis de análise, além do conhecimento das particularidades das pessoas que fazem a política externa, uma vez que reconhecem que diferentes escolhas podem ser feitas em cenários semelhantes.

A esses elementos característicos da Segunda Geração somam-se, a partir da obra de Harold e Margaret Sprout (1956), elementos contextuais e as características das lideranças tais como seus aspectos cognitivos. Em linhas gerais, partem da premissa de que a mente de um formulador e decisor não é uma tabula rasa, pois carrega ideologia, cultura, emoções entre outros aspectos cognitivos e sociais que influenciarão na forma de reconhecer o problema, nas decisões que se irá tomar, bem como na própria representação da situação. Essa tradição é também conhecida como Foreign Policy Context (Hudson ; Vore, 1995).

Essas abordagens buscam superar as análises que consideram o Estado como um ator monolítico, em que o interesse nacional se confunde com o próprio interesse de Estado. Em outros termos, o objetivo é se afastar do "dever ser" ou da perspectiva idealizada de organização do Estado em matéria internacional proferidas pelas abordagens clássicas predominantes até o final da Guerra Fria, para se aprofundar no conhecimento de algo que era tido como inexistente ou sem importância no processo de apreensão de assuntos relativos à política externa e às decisões políticas.

O caráter "interméstico", cada vez mais predominante nas temáticas presentes nas agendas diplomáticas dos Estados, dificulta uma apreensão muito clara sobre o que é interno e o que é externo. Exemplos disso, são as questões de preservação ambiental, respeito aos direitos humanos, direitos da criança e do adolescente, políticas comerciais, financeiras entre outras diversas problemáticas. Sendo assim, a aplicabilidade teórico-conceitual e metodológica de análise de políticas públicas torna-se uma importante ferramenta para avaliar as etapas dos processos políticos, quais sejam: inputs, formação da agenda, for- 
mulação da política, processo decisório, implementação, avaliação e outputs. Assim, nas palavras de Salomón e Pinheiro:

(...) a política externa é uma política pública, embora com uma especificidade que a diferencia do resto das políticas públicas: o fato de ser implementada fora das fronteiras estatais, o que pode levar a uma distância considerável entre objetivos e resultados (2013:41).

Frey (1997) também destaca que para se compreender as etapas do processo político é necessário que as dimensões que diferenciam a análise política sejam apresentadas: a dimensão institucional (polity), cujo propósito é compreender o sistema político, o quadro normativo e institucional que abarcam as políticas; a dimensão processual (politics), que trabalha com os meandros, ou seja, caminhos pelas quais passam as políticas e as influências que sofrem ao longo do processo; e, finalmente, a dimensão material (policy), que trata efetivamente do conteúdo das políticas.

Assim, a interação sistêmica entre as variáveis não pode ser considerada a partir de uma relação determinística de causalidade, isto porque os inputs são permeados por regras, instituições, atores, preferências, entre outros fatores presentes na "caixa" decisória do Estado que irá filtrar as demandas nem sempre convergentes articuladas por cenários múltiplos e complexos que determinarão o resultado da política. E é essa dinâmica no interior do processo de tomada de decisão que muitos autores focalizaram suas análises.

Allison e Zelikow (1999), por exemplo, na obra Essence of Decision construíram tipologias que possibilitaram um debate mais estreito em relação ao papel exercido pela burocracia na política. $\mathrm{O}$ primeiro modelo conceitual, chamado de "política racional" se apoia na noção de Estado unitário, cujo comportamento é analisado como se fosse um indivíduo, cujas ações estão permeadas pela função utilidade, sendo as escolhas resultado da melhor opção custo-benefício. Essa abordagem se aproxima da concepção realista de atuação do Estado nas relações internacionais, sendo entendidos como unificados os atos dos governos nacionais, ou seja, não é pressuposta a existência de conflitos de interesses internos como fatores influentes na determinação da política externa. 
No segundo modelo, os autores desenvolvem o chamado "modelo burocrático organizacional", em que as escolhas e ações são antes outputs de grandes organizações, funcionando segundo modelos regulares de comportamento. Nesse caso, a origem das ações dos atores são menos escolhas deliberadas de líderes e mais resultados das grandes organizações. Para o desenvolvimento desse modelo, cada organização se ocupa de um conjunto particular de problemas com uma independência quase que total: os atores agem submetidos às regras formais de funcionamento da organização, sendo as preferências moduladas pelos procedimentos burocráticos. As decisões políticas, portanto, são resultados da interação com as diversas organizações governamentais, que seguem procedimentos operacionais padrões, $\mathrm{o}$ que significa que nesse modelo as burocracias não são consideradas atores políticos e, sim, administradores que executam ações mediante a inércia burocrática, buscando cristalizar políticas e preferências. Para a realização desses trabalhos complexos de rotinas, as ações individuais são coordenadas por regras e programas preestabelecidos, ou seja, as amarras burocráticas impedem o indivíduo de agir.

Já no terceiro modelo conceitual, intitulado "político-burocrático", os autores desenvolvem a ideia de que a política externa seria o resultado de um complexo processo de barganha entre as burocracias que compõem o Executivo, cada qual com seus próprios objetivos em matérias relativas a essa área e com inserções próprias dentro do processo decisório. Além da diferença entre as preferências e objetivos entre as organizações, o aspecto individual também é incorporado no modelo, uma vez que cada um é considerado como um jogador dentro da política burocrática com seus próprios interesses e preferências. Portanto, nesse caso, as decisões de política externa não são consideradas mais como resultantes de uma escolha racional de um governo unitário, tampouco como resultado de procedimentos operacionais formais, mas compostos por uma interação mútua entre atores com suas próprias preferências, agindo dentro de organizações também com interesses próprios.

Essa terceira tipologia desenvolvida por Allison e Zelikow (1999) nos remete a um debate que vem sendo encampado por alguns autores na compreensão da natureza contemporânea do Estado, e que vem adquirindo uma característica de atuação de rede, menos hierarquizada, e mais complexa e dinâmica, a fim de responder a processos cada vez mais abrangentes e multifatoriais. Esse debate também tem envolvido 
o questionamento sobre os mecanismos de controle democráticos existentes sobre esses atores, uma vez que são administradores públicos que assumem o cargo por competência técnica, estando aquém do controle do eleitorado. Sendo assim, se pensarmos o cenário atual, do ponto de vista conceitual, os limites da accountability clássica são também evidentes em virtude de uma complexidade institucional muito maior, sendo que a implementação de políticas requer, nos dias de hoje, a cooperação entre diversas agências que estão organizadas em networks, diferenciando-se, portanto, do padrão anterior, que organizava suas ações através da setorização das políticas públicas (Behn, 1998).

A proposta do modelo de administração gerencial nasce também nessa fase de questionamento sobre as funções que o Estado deveria desempenhar frente à economia e à sociedade. Nesse contexto, colocou-se em debate aspectos centrais das premissas do modelo burocrático (racional-legal) em vigor em grande parte do mundo até pelo menos a década de 1980 (Abrucio, 1997). Dentre os principais questionamentos estavam a ineficiência gerada pelo sistema que tinha como objeto o rigor nos processos sem, contudo, dar a devida relevância aos resultados; a hierarquia e centralização dos processos, dificultando ações mais autônomas por parte das unidades de gestão. Sendo assim, a demanda passou a estar orientada para ferramentas que permitiriam transparência, efetividade, foco nos resultados, gestão por projetos, diálogo mais estreito e horizontalizado com outras repartições burocráticas e mais mecanismos de participação popular sobre as decisões do Estado (Bresser-Pereira, 1997).

No Brasil, esses questionamentos a respeito dos modelos de gestão pública chegam mais tardiamente, ganhando dimensão propositiva em meados da década de 1990, com a reforma administrativa do Estado ocorrida durante o governo de Fernando Henrique Cardoso. Contudo, embora uma série de recomendações e determinações tenham sido realizadas nesse período da história brasileira, atualmente ainda se preservam traços importantes do modelo de gestão burocrática, com sobreposição de modelos (Figueira, 2009).

Diante disso, à luz dessas proposições analíticas, a proposta deste artigo é observar essa dinâmica decisória da área de promoção comercial brasileira a partir de um quadro de transformações de ordem sistêmica (doméstica e internacional) ocorridas nas últimas décadas. 


\section{METODOLOGIA DE PESQUISA}

Este estudo é de natureza qualitativa, exploratória, descritiva, baseada no método do estudo de caso, que propicia ter uma visão aprofundada, integrada, contextualizada e longitudinal do processo. Embora esse método inviabilize a generalização estatística dos resultados, ele permite ao pesquisador mergulhar intelectualmente na realidade explorada. Além disso, como bem destaca Yin (1994) é um método em que não há controle sobre os eventos, sendo ele também adequado para estudo de fenômenos contemporâneos, que requerem observações em profundidade. Outro destaque para escolha do método é a insuficiência de pesquisas produzidas na atualidade sobre a dinâmica institucional e decisória que compõem a história da promoção comercial no Brasil, sendo que a maioria dos estudos dessa área está direcionada exclusivamente em compreender os outputs, ou seja, os resultados da política.

Além disso, como um desafio complementar, este artigo propõe uma análise integrativa entre diferentes áreas do conhecimento, tais como: Ciência Política, Relações Internacionais e Gestão Pública. Essas áreas, de forma complementar, ofereceram visões específicas dentro da dinâmica estudada, possibilitando uma interpretação transversal e mais completa do fenômeno.

A escolha do tema foi realizada considerando as mudanças históricas ocorridas nas políticas de promoção comercial no Brasil, que vêm respondendo de forma bastante evidente às demandas cada vez mais complexas e interdependentes interpostas pelos ambientes doméstico e internacional. Além disso, a seleção do caso levou em consideração as alterações no formato da gestão pública da área, que foi se adaptando à medida que as dinâmicas sistêmicas pressionavam por respostas mais integradas, transparentes e participativas. Desse modo, entendeu-se que o caso selecionado para análise é potencialmente representativo, dos quais as lições apreendidas são informativas em relação à média (Yin, 1994).

Quanto ao processo de coleta dos dados, foi realizada a técnica de triangulação, considerando dados primários e secundários provenientes do levantamento bibliográfico em jornais, livros e periódicos especializados, informações governamentais disponíveis nos sites oficiais, tais como: Ministério das Relações Exteriores, Ministério de 
Desenvolvimento Indústria e Comércio, Banco Nacional de Desenvolvimento Econômico e Social, Câmara de Comércio Exterior (Camex), Agência Brasileira de Promoção de Exportações e Investimentos (APEX) e documentos internos. A triangulação em pesquisas dessa natureza é de suma importância, pois permite minimizar possíveis vieses ou erros de interpretação do pesquisador.

Por fim, como um dos objetivos é verificar como a estrutura burocrática do Estado, numa determinada área vem respondendo às transformações sistêmicas, absorvendo as demandas e reagindo a elas, dividiu-se, para análise de conteúdo, o percurso histórico recente desses rearranjos em três fases, sendo elas: 1 ) as políticas restritivas às importações e os arranjos centralizados de promoção ao comércio exterior; 2) a reestruturação institucional das agências de promoção ao comércio exterior brasileiro em face da liberalização econômica; e 3) a estruturação e consolidação de políticas de atração e promoção do Investimento Direto Externo (IDE). Cabe ressaltar, porém, que essa divisão proposta tem por finalidade dar compreensão e organicidade intelectual ao conteúdo histórico, o que não significa dizer, logicamente, que ela seja fragmentada e dividida cartesianamente em ciclos.

\section{ESTUDO DE CASO: O BRASIL E OS REARRANJOS INSTITUCIONAIS NAS ÁREAS DE PROMOÇÃO E SUPORTE COMERCIAL}

\section{As Políticas Restritivas às Importações e os Arranjos Centralizados de Promoção ao Comércio Exterior}

A mudança no padrão de comércio exterior brasileiro começou a ganhar destaque no governo de Getúlio Vargas com algumas iniciativas de protecionismo comercial como ferramenta de incentivo à industrialização nascente no país. Esse processo ganhou força tanto no Brasil como na América Latina entre as décadas de 1950 e 1980, com a concepção do Estado desenvolvimentista, em que a política de substituição de importações era um dos métodos para resguardar as indústrias ainda prematuras do país diante da concorrência internacional (Vicari, 2010).

Assim também, com o intuito de formular e coordenar as políticas de comércio exterior foi criado, no governo Castello Branco, um órgão colegiado interministerial, inicialmente denominado de Comissão de 
Comércio Exterior (CCE) e, posteriormente, substituído pelo Conselho Nacional de Comércio Exterior (Lei 5.025/1966) (Ramos, 2008). Contudo, como ressaltado por diversos analistas (Nassif, 1995; Veiga e Iglesias, 2002; Fernandes, 2010), embora o propósito naquele momento fosse dar força ao órgão colegiado, privilegiando a coordenação de posicionamentos, observou-se empiricamente o caráter figurativo desempenhado pelo Conselho em relação à Carteira do Comércio Exterior do Banco do Brasil (Cacex), que de fato dominava as decisões da área, pois detinha o poder da operacionalização da matéria.

Desse modo, questões envolvendo as ferramentas operacionais de gestão do comércio exterior durante grande parte do período foram de responsabilidade da Cacex (Ministério da Fazenda), que deteve a dominância decisória, enquanto as negociações internacionais e a promoção comercial ficavam a cargo do Ministério das Relações Exteriores (MRE). Contudo, a convergência de posições interministeriais em relação à política econômica de substituição de importações começa a ser abalada por volta da década de 1970, à medida que o Brasil passa a ser pressionado por outras nações a oferecer contrapartidas nas negociações multilaterais do comércio. Um exemplo ocorreu antes mesmo de iniciar a Rodada de Tóquio (1973-79), assim como narra Farias (2007). O Brasil tinha conseguido um Waiver para mudar suas tarifas e recompor a Lista III de concessões, de modo a atender demandas por reciprocidade, como no caso dos britânicos, que solicitavam melhores condições nas negociações de tratores e uísques. Segundo o autor, esse foi o começo do embate de forças entre as estruturas de apoio doméstico ao comércio (como a Cacex, caracterizada pelo seu viés altamente protecionista), e as de atuação externa, como o MRE, que crescentemente passava a ter que responder pelas demandas liberalizantes do GATT (General Agreement on Tariffs and Trade).

Como resultado desse cenário emergente, houve uma alteração no modo de se construir a posição negociadora do país no âmbito internacional, como ocorrido na Rodada de Tóquio. Segundo Farias (2007), até então o Itamaraty consultava os órgãos domésticos como meros ratificadores de posicionamento já delineados previamente pelo corpo diplomático. O Decreto 72.161, de 30 de abril de 1973, porém, altera essa dinâmica ao criar uma Unidade de Negociação, responsável por coordenar e definir o posicionamento a ser adotado pelo Brasil no âmbito do GATT através do diálogo interburocrático 
institucionalizado. Nesse caso, embora o Itamaraty tenha mantido o controle relativo do processo, ao ganhar a presidência do órgão, ele foi exposto ao diálogo com os demais órgãos, tais como: Ministério da Fazenda, Ministério da Indústria e Comércio, Ministério do Planejamento e Coordenação Geral, Banco do Brasil. Sendo assim, progressivamente observou-se a necessidade de apoio técnico de outros órgãos, tamanha era a complexidade que iam adquirindo as negociações comerciais internacionais. Ao mesmo tempo, isso levou a uma pressão pelo antigo modelo operacional desse Ministério, acostumado a atuar de forma insulada (Barros, 1986).

Daí por diante, as negociações e seus contenciosos passaram a girar mais do que nunca em duas frentes (doméstica e internacional), tornando o processo mais complexo e menos centralizado. Um dos primeiros conflitos burocráticos se deu logo no início, no processo de elaboração da lista de concessões a ser apresentada na Rodada de Tóquio. $\mathrm{O}$ argumento do tratamento diferenciado para países em desenvolvimento, ancorado na premissa de que se necessitaria dar suporte à indústria nascente, predominante nos discursos brasileiros nos foros multilaterais, já não era mais o suficiente para manter o país efetivamente dentro das negociações do GATT. Assim, como apontado por Farias (2007), para evitar o isolamento diplomático, o Itamaraty propôs uma lista de concessões, recusada, posteriormente, pelos membros Cacex (Fazenda). Esse impasse só teria sido solucionado pelo presidente Geisel no início do seu mandato (1974), dando prosseguimento e razão ao apelo feito pelo Ministério das Relações Exteriores.

Essa primeira experiência de interlocução mais estruturada de diálogo ministerial na confecção de posicionamento externo seria repetida poucos anos depois, já no processo de preparação para a Rodada do Uruguai (1986-94). Mas dessa vez o Itamaraty propôs uma nova estrutura de coordenação apoiada em comissões interministeriais mais temáticas, tais como: Grupo Interministerial de Bens (GIB) e o Grupo Interministerial de Serviços (GIS).

Sendo assim, em busca de interpretar esse fenômeno, Alexandre Barros em seu texto A Formulação e Implementação da Política Externa Brasileira: o Itamaraty e os Novos Atores, destaca as dificuldades enfrentadas por este Ministério de manter sob seu comando algumas temáticas transversais de política externa, que incluem outras áreas de atuação governamental, especialmente o comércio exterior. Para o autor, as de- 
cisões referentes a essa área passaram a ficar cada vez mais difíceis após a década de 1970, fazendo com que o Itamaraty passasse por um processo de repensar suas responsabilidades e estratégias. Suas ações, nesse momento de pressão, foram de mistura de supervisão e auxílio, o que, segundo o autor, foi uma maneira encontrada de manter o controle sobre os rumos da política externa em suas diferentes frentes.

Até a década de 1970, as agendas diplomáticas dos Estados estiveram predominantemente concentradas em temas da alta política (agenda de segurança), caracterizada pelo alto grau de sigilo e sensibilidade das temáticas interestatais. Após esse período, porém, os temas softs (comércio, meio ambiente, direitos humanos etc.) emergiram como pauta central nos debates internacionais (Keohane; Nye, 1998) e, consequentemente, no caso do Brasil, a concentração do poder decisório no Itamaraty e sua dinâmica altamente insulada passam a ser problematizadas, uma vez que as questões de política externa com características multidimensionais demandavam frequentemente uma dinâmica interativa entre burocracias federais, bem como um diálogo mais estreito entre os poderes Executivo e Legislativo na conformação das posições internacionais do Brasil (Figueira, 2009).

O avanço nas negociações multilaterais do comércio, a aceleração do processo de globalização já em curso, a elevação da mobilidade de bens e serviços, o aumento da concorrência internacional e a busca crescente por parte das empresas de acessarem o mercado internacional, seja para expansão de seus negócios, seja para sobreviver numa economia global cada vez mais interdependente, foram alguns novos inputs gerados pelo sistema que encaminharam a inauguração de uma nova fase na promoção comercial brasileira e no modus operandi do sistema de apoio à área (Lima; Santos, 2001).

Adicionalmente, as crises dos Estados de Bem-Estar social na Europa e nos Estados Unidos, as crises do petróleo de 1973 e 1979, a “década perdida" de não crescimento que se sucedeu na América Latina, associado aos fatores políticos internacionais, como o desfecho da Guerra Fria e as forças resultantes das políticas liberalizantes do Ocidente foram fatores de ordem sistêmica que levaram ao final do ciclo e originaram uma nova fase de reorientação da política e da promoção comercial brasileira.

É também neste contexto que a Cacex (Carteira de Comércio Exterior do Banco do Brasil, vinculado ao Ministério da Fazenda) passa por 
um processo lento de esvaziamento até sua desativação no governo Collor (1990-92). Sobre a Cacex, Veiga e Iglesias (2002) ressaltaram a ausência de transparências dos mecanismos de gestão, bem como a maneira informal e setorizada em que ocorriam as articulações com a esfera privada. Com isso, em um contexto em que a política de comércio exterior não respondia mais de forma adequada às variáveis decorrentes de um cenário em plena transformação, o processo foi se esgotando lentamente.

\section{Reestruturação Institucional das Agências de Promoção ao Comércio Exterior Brasileiro diante da Liberalização Econômica}

Essas alterações estruturais ocorridas no sistema internacional no período pós-Guerra Fria foram convergentes com as grandes transformações que vinham acontecendo no cenário doméstico brasileiro. Com um processo de redemocratização em curso e a busca por uma política econômica capaz de superar a fase anterior de recessão, o início da década de 1990 foi caracterizado, em grande parte, pelo plano de liberalização econômica iniciado no governo Collor (1990-92), processos de privatizações com a proposta de redução do tamanho e do próprio papel desempenhado pelo Estado. Nos governos subsequentes (Itamar Franco e Fernando Henrique), houve a busca pela estabilização do Plano Real e as tentativas de reestruturação da gestão pública seguindo um padrão mais gerencial (Benh, 1998).

Foi, portanto, nessa nova fase, inaugurada no governo Collor, que a Cacex foi desativada e suas antigas funções transferidas para o Departamento de Comércio Exterior (Decex), submetido ao condensado Ministério da Economia, Fazenda e Planejamento (MEFP) (Ramos, 2008). A esse novo Ministério coube a responsabilidade de conduzir as políticas econômica, industrial e de comércio exterior, reunindo inúmeras atribuições, o que teria levado o Itamaraty, segundo Fernandes (2010), a resistir a uma possível perda de espaço, buscando firmar seu posicionamento histórico como órgão negociador dessa agenda no plano internacional.

Essa alteração de ordem institucional teve como pano de fundo a mudança brusca de orientação da política comercial brasileira do período, cuja proposta foi iniciar um ciclo de liberalização econômica, convergente com as dinâmicas de outros países do mundo e com a confecção de modalidades de comércio preferencial 
(blocos regionais), como o caso da criação do Mercado Comum do Sul (Mercosul). Nesse contexto, Castelan (2009) argumenta que, a despeito das funções exercidas pelas agências burocráticas atuantes na área do comércio exterior ainda estarem nebulosas e fragmentadas desde o governo Sarney (1985-90), a condução da política interna se deu em consonância com as posturas adotadas pelo Brasil no âmbito multilateral no período, o que, segundo ele, teria sido resultado de um relativo consenso construído entre os Ministérios da Fazenda e das Relações Exteriores. Para o autor, o papel de condutor das políticas econômica e comercial assumido pela Presidência da República foi fundamental para esse processo, à medida que os cargos estratégicos dessa área no governo foram ocupados por pessoas vinculadas aos ideais liberalizantes e as equipes mais alinhadas a premissas nacionaldesenvolvimentistas acabaram afastadas dessas funções.

Já no governo Itamar Franco (1993-94) houve uma nova configuração institucional para área comercial, sendo criado, a partir de uma reforma administrativa, o Ministério da Indústria, Comércio e Turismo sob o qual recaíram as atribuições da antiga Cacex, sendo as ações de política de comércio exterior direcionadas para a Secex (Secretaria de Comércio Exterior) e seus respectivos departamentos ${ }^{1}$. Em outros termos, significa dizer que o "super" Ministério criado no governo antecessor (Fernando Collor) foi desmembrado e suas funções descentralizadas entre diferentes repartições burocráticas do Estado, levando novamente a um cenário de desorientação estratégica.

Essas confusões foram percebidas nos resultados, pois, mesmo após as reformas precedentes, não houve evolução expressiva, nem sob o ponto de vista de balança comercial superavitária, tampouco no que se refere à coordenação das ações interinstitucionais direcionadas ao comércio exterior.

Tabela 1

Comércio exterior brasileiro - US\$ (Bilhões) (1990-1993)

\begin{tabular}{cccc}
\hline Ano & Exportações & Importações & Saldo comercial \\
\hline 1990 & 31,4 & 20,7 & 10,8 \\
1991 & 31,6 & 21 & 10,6 \\
1992 & 35,8 & 20,6 & 15,2 \\
1993 & 38,6 & 25,3 & 13,3 \\
\hline
\end{tabular}

Fonte: Informações organizadas pelo autor com dados do Ministério da Indústria, Comércio Exterior e Serviços (MDIC), 2016. 
Diante disso, no primeiro mandato do governo Fernando Henrique (1994-97), frente ao desafio de potencializar o comércio exterior brasileiro e solucionar a problemática de coordenação política interministerial que se mantinha fragmentada desde a extinção da Cacex, foi criada, em 1995, a Câmara de Comércio Exterior (Camex), vinculada ao Conselho de Governo da Presidência da República. Suas diretrizes originalmente foram delimitadas da seguinte forma (Decreto 1.386/1995):

1) Definir as diretrizes da política de comércio exterior; 2) Manifestarse previamente sobre as normas e legislação sobre o comércio exterior e temas correlatos; 3) Dispor sobre as diretrizes para as alterações das alíquotas dos impostos de importação e exportação; 4) Estabelecer as diretrizes para as investigações relativas a práticas desleais de comércio exterior; 5) Fixar as diretrizes para a política de financiamento e de seguro de crédito às exportações; 6) Estabelecer as diretrizes para a política de desregulamentação do comércio exterior; 7) Avaliar o impacto das medidas cambiais, monetárias e fiscais sobre o comércio exterior; 8) Formular a política sobre a concessão de áreas de livre-comércio, zonas francas e zonas de processamento de exportações; 9) Fixar as diretrizes para a promoção de bens e serviços brasileiros no exterior; 10) Indicar os parâmetros para as negociações bilaterais e multilaterais relativas ao comércio exterior.

Segundo Fernandes (2010) a criação da Câmara teria sido resposta às pressões exercidas pelos Ministérios da Fazenda e das Relações Exteriores que eram contrários à ideia de criação de um Ministério do Comércio Exterior, que centralizaria todas as atividades relativas à área. Particularmente sobre esse episódio de resistência burocrática em função da possibilidade de ingresso de um novo ator político-institucional na configuração de forças de um governo, Niskanen (1971) traz uma grande contribuição analítica para o caso, ao considerar a disputa por orçamento, o espaço dentro do governo e poder de decisão como fatores-chaves para explicação do perfil de comportamento das burocracias dentro do sistema político.

Nesse contexto, como resultante do processo que ainda se mantinha com grande lacuna institucional, a Camex é constituída com o propósito de definir os parâmetros da política de comércio exterior do país e servir como conselho consultivo capaz de coordenar as preferências dos diferentes Ministérios envolvidos com o tema, diminuindo a fragmentação caracterizada no governo anterior. Naquele momento, 
esse órgão foi formado pelos Ministros da Casa Civil, das Relações Exteriores, da Fazenda, da Indústria, Comércio e Turismo, do Planejamento, Orçamento e Gestão, da Agricultura e Abastecimento, e do Banco Central (Decreto 1.386/1995).

Embora inicialmente com capacidade decisória limitada, a iniciativa de criação de um órgão de coordenação e de revisão do processo de confecção da política de comércio exterior nacional, levou as antigas estruturas administrativas a terem que repensar seu modus operandi, arraigadas ainda no formato tradicional e centralizado. O Itamaraty, que já vinha desenvolvendo alguns ajustes na sua estrutura interna com o objetivo de melhor atender às demandas incipientes, criou em 1993, em resposta às recomendações do Programa de Eficiência Comercial lançado pela Conferência das Nações Unidas sobre Comércio e Desenvolvimento (Unctad-1992), os Pontos de Comércio, cujo propósito foi o de melhorar a circulação de informações comerciais e as oportunidades de negócios, vinculados os agentes em uma rede global (Vicari, 2010).

Todavia, as transformações mais substantivas começaram a ocorrer mesmo após 1997, quando a Camex definiu um conjunto de metas e subprogramas, em que os Ministérios Partes deveriam atender dentro de seus respectivos escopos de atuação. Ao MRE coube:

Promoção ao comércio exterior; inserção de pequenas e médias empresas; eliminação de constrangimentos internos à exportação; negociações e integração comercial; eliminação de constrangimentos externos à exportação e aprovação de uma Lei de Comércio Exterior.

Nessa direção, Vicari (2010) destaca o processo de resposta do Ministério das Relações Exteriores à reestruturação institucional que vinha ocorrendo. Após a contratação da consultoria Booz Allen \& Hamilton, o Itamaraty se confrontou com três possíveis cenários, sob os quais deveria desenhar seu plano estratégico para a área nos próximos anos, sendo eles: 1) desconectar-se em definitivo da tarefa de promoção comercial, deixando esta tarefa para outras repartições burocráticas da administração direta; 2) atuar apenas nas áreas de inteligência comercial e representação, dividindo, portanto tarefas com demais órgãos governamentais que atuam na área de comércio exterior no Brasil; 3) englobar uma extensa gama de atividades, envolvendo desde a inteligência comercial e representação, como apon- 
tado no segundo cenário, como também tarefas de demonstração e facilitação de novos negócios. O autor ressalta que o cenário selecionado pelo Ministério para prosseguir suas atividades foi o segundo, tendo em vista a limitação de recursos que impedia a ampliação de sua atuação na área, assim como, na outra ponta, a ausência total implicaria na perda de domínio de uma pauta importante da agenda diplomática brasileira, ou seja, um cenário indesejado.

Diante dessa definição de funções após a criação da Camex e com vistas a atingir as metas estabelecidas nos subprogramas foi redesenhada a rede de representação do MRE no exterior através dos Setores de Promoção Comercial (Secoms) locais; diminui-se em números essas representações de 117 para 52, ao mesmo tempo em que se buscou potencializar a capacidade de resposta estratégica dessas repartições. Para articular toda essa rede foi criada, em 1998, o BrasilTradeNeT², sistema online de promoção comercial, possibilitando uma melhor captação e respostas às demandas incipientes, disseminando, através de um sistema online, conhecimentos e informações dessa área (Vicari, 2010). Foram ainda criados canais de interlocução institucionalizada com o empresariado nacional, tais como Senalca (Seção Nacional de Coordenação dos Assuntos relativos à Área de Livre Comércio das Américas (Alca)) e a Seneuropa (Seção Nacional de Coordenação dos Assuntos relativos às negociações Mercosul-União Europeia), funcionando como fóruns consultivos sobre processos de integração comercial em curso (Figueira, 2009).

Ademais, como forma de reestruturação do aparato de apoio ao comércio exterior, houve um esforço no segundo mandato do governo de Fernando Henrique Cardoso (1998-2002) em duplicar as exportações até 2002. Para tanto, criou-se, em 1998, um Programa Especial de Exportações, que envolveu a elaboração de "Termos de Referências", que identificava fragilidades e potencialidades de cada setor para competição no mercado internacional (Veiga; Iglesias, 2002). Assim, buscando mapear o grau de competitividade de cada categoria, foi criada, em 1997, a APEX-Brasil (Agência Brasileira de Promoção de Exportações e Investimentos), no âmbito do Sebrae, com o propósito de promover o comércio exterior brasileiro, direcionando-se especialmente para atuação junto às micro e pequenas empresas ${ }^{3}$.

Ao longo deste período, as reestruturações na dinâmica decisória da área comercial e nos canais de acesso ao governo dos atores não es- 
tatais foram acompanhadas de mudanças progressivas também no conteúdo das políticas e no perfil negociador brasileiro nas arenas multilaterais de comércio. No decorrer da Rodada do Uruguai, inaugurada em 1987, o posicionamento brasileiro se alterou de uma posição defensiva para proativa. Isso porque, nesse período, em razão da reformulação na política tarifária, foi possível estabelecer uma articulação convergente com os diferentes órgãos do governo, através do Subgrupo de Acesso a Mercados do GIB, de modo a sustentar as ofertas brasileiras nas negociações internacionais (Ramos, 2008).

Além disso, a temática da Agricultura passa a ter destaque nas negociações do GATT, engendradas pelas demandas levadas pelo grupo de Cairns (constituído originalmente por 13 países exportadores agrícolas) que buscava, em linhas gerais, condições mais favoráveis no acesso a mercados de países desenvolvidos (Thortensen, 2001). Nesse caso, embora o Brasil tenha sido parte constituinte do grupo, não apresentou, ainda nessa fase, uma liderança, como viera a ocorrer anos depois no âmbito do G-20/OMC.

Nessa mesma direção, a pulverização relativa dos espaços de representação nas negociações internacionais, contando com a participação de diversos atores estatais e não estatais, também foi observada nas negociações da Alca. Como ressaltam Mancuso e Oliveira (2006), o despreparo percebido pelos empresários brasileiros quando enfrentados pelos grupos de interesses norte-americanos nas rodadas de negociações da Alca, levou a Confederação Nacional da Indústria (CNI) a mobilizar o empresariado nacional através da criação, em 1996, de uma organização suprassetorial denominada Coalizão Empresarial Brasileira (CEB). Como ressalta Carvalho (2003), a CEB passou a ser o órgão de articulação entre o setor produtivo e o governo nas negociações multilaterais; mas, além disso, outras representações emergiram neste contexto, tal como o Fórum Permanente de Negociações Agrícolas Internacionais e a Rede Brasileira de Integração dos Povos (Rebrip) (Oliveira; Milani, 2012).

Portanto, essa segunda fase foi caracterizada por diferentes momentos na trajetória da promoção comercial brasileira, tanto no que se refere ao conteúdo das políticas, como em relação à estrutura decisória. As pressões de ordem sistêmica associadas às variáveis endógenas ao processo levaram a criação de uma arquitetura interinstitucional capaz de lidar com um tema altamente complexo de forma horizon- 
talizada, envolvendo progressivamente repartições com alguma atividade de interlocução direta com o ambiente externo.

\section{A Estruturação e Consolidação de Políticas de Atração e Promoção do Investimento Direto Externo (IDE).}

A crise econômica, o fraco desempenho nas exportações e a desvalorização do real frente ao dólar caracterizaram o final da década de 1990, ensejando, porém, a projeção de um novo ciclo de crescimento na década seguinte.

Figura 1

Balanca comercial brasileira /décadas

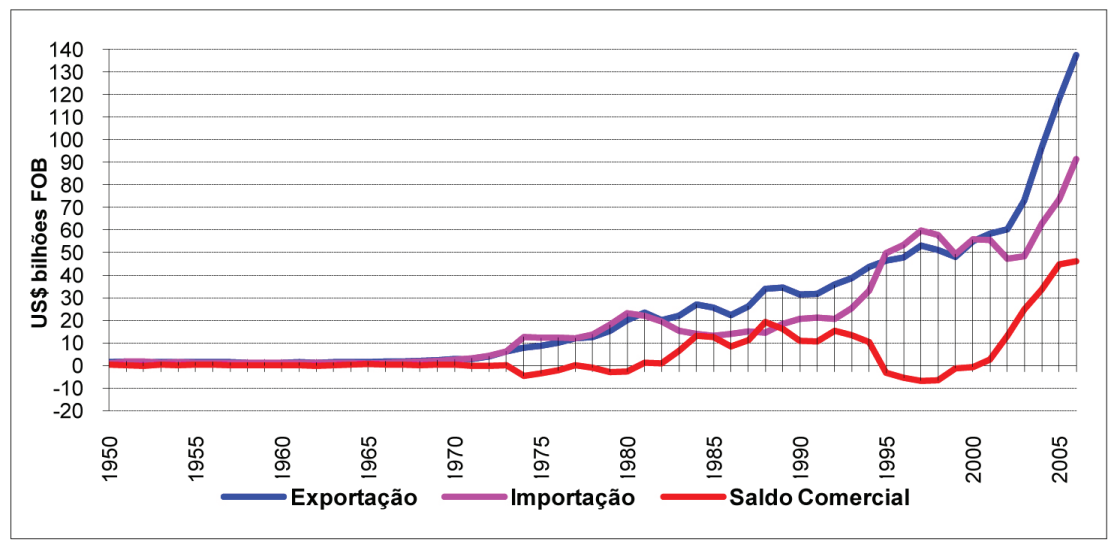

Fonte: MDIC (2016).

Essa nova fase da economia nacional, alavancada por perspectivas positivas, também elevou o número de empresas brasileiras com grau de comprometimento maior no mercado externo, ou seja, avançando para outras modalidades de imersão no comércio internacional. Assim também, a entrada de capitais no país através de investimento direto externo também foi crescente, muito em virtude dos patamares alcançados pelo Brasil na década, levando-o inclusive a integrar coalizões internacionais estratégicas como o G-20 financeiro e o arranjo cooperativo dos BRICS4.

Nesse contexto, alguns ajustes na estrutura institucional também foram realizados, já que mesmo com a tentativa anterior de coordenar as ações antes fragmentadas entre diferentes estruturas burocráticas 
federais, ainda se percebia uma dispersão. Isso porque, como ressaltam Veiga e Iglesias (2002), a Camex era apenas um órgão consultivo, sem capacidade decisória e sem o comando geral das diretrizes da promoção comercial. Além disso, outra grande dificuldade encontrada estava no próprio sistema de tomada de decisão, uma vez que o mesmo previa consenso entre os ministros, o que significava em grande medida que parte dos problemas acabava sendo escoada para que a Presidência da República resolvesse.

Sendo assim, segundo Fernandes (2011), em 2001, a Câmara passou por uma reforma estrutural (Decreto 3.981/2001), em que previa a constituição do Comitê de Gestão da Camex. Com essa alteração, a construção do consenso em matérias específicas do comércio exterior caberia aos secretários executivos dos ministérios, passando para os Ministros das respectivas pastas apenas as decisões em que já estavam costurados os consensos. Isso evitou que grande parte das decisões fosse levada até a Presidência.

Outro aspecto destacado por Veiga e Iglesias (2002) foi o fato da Camex, nessa reformulação, ser incorporada pelo MDIC, o que a fez perder o caráter anterior supraministerial; aumentando, com isso, as disputas entre as burocracias federais e levando a uma perda relativa de poder decisório do colegiado.

Outro órgão governamental que também sofreu significativas alterações nesse contexto foi o BNDES, que através de um novo estatuto, estabelecido pelo decreto 4.418 , de 2002, possibilitou a abertura de uma linha de crédito para o fomento da internacionalização de empresas brasileiras:

Art. 9. II: financiar a aquisição de ativos e investimentos realizados por empresas de capital nacional no exterior, desde que contribuam para o desenvolvimento econômico e social do País 5 .

Com isso, o banco passou a atuar mais significativamente na área, contribuindo para o processo de operacionalização de crédito para investimento no exterior, aumentando o grau de internacionalização da economia nacional. Nessa mesma direção, foi criado o Comitê de Financiamento e Garantia das Exportações (Cofig) pelo Decreto 4.993/2004', um órgão colegiado reunindo MDIC, MRE, MF, Ministério Agricul- 
tura, Pecuária e Abastecimento (Mapa), MPOG e Casa Civil. O Órgão é responsável pelo estabelecimento dos parâmetros de financiamento e garantia de créditos, considerando, para tanto, todos os elementos estratégicos para o país da operação em análise.

Assim, nessa terceira fase, além da reestruturação do principal órgão de articulação entre as burocracias envolvidas com o comércio exterior (Camex) e a agência e o colegiado envolvidos com a operacionalização de crédito nas garantias às exportações (BNDES/Cofig), o MRE, apoiador informacional, facilitador no desenvolvimento de novas oportunidades de acesso a mercados, e negociador dos acordos internacionais de comércio, continuou o seu processo de reestruturação e aperfeiçoamento interno para atender essa área. Atualmente, o Departamento de Promoção Comercial e Investimentos do Itamaraty conta com uma arquitetura de apoio constituída por Secoms distribuídos por pontos estratégicos no Globo, bem como pontos focais espalhados por todo o Brasil com objetivo de viabilizar a projeção externa de diferentes negócios. Existem no total 58 pontos focais e 104 Secoms, em 82 países (MRE, 2017).

Dentre as principais funções desse departamento estão: atração de investimentos, promoção da internacionalização de empresas do país, promoção de diálogos internacionais para comércio e investimentos, elaboração de estudos sobre projeções de investimentos do Brasil no Exterior, apoio às missões comerciais e participação nos órgãos colegiados que decidem sobre os rumos da política de promoção comercial brasileira ${ }^{7}$.

Assim também, os diálogos entre empresa e governo foram intensificados nas arenas das negociações comerciais internacionais. Na virada da década (1999), foi criado um Grupo de Trabalho sobre Comércio Internacional de Mercadorias e Serviços (GICI) direcionado para formulação do posicionamento brasileiro no âmbito da Rodada do Milênio da Organização Mundial do Comércio (OMC). Porém, essa estrutura, como aponta Carvalho (2003), funcionou apenas como canal consultivo, em que os atores não estatais eram convidados de forma seletiva e com frequência variável, tendo pouco ou nenhum papel na construção do processo negociador.

Diferentemente, porém, foi a atuação da classe empresarial nos desdobramentos da Rodada de Doha. Já em 2003, com o propósito ini- 
cial de avançar nas negociações referentes à agricultura e impedir, como ferramenta de barganha, o andamento de negociações que envolvessem outros interesses, o Brasil, juntamente com a Índia, protagonizou a criação do G-20 (grupo formado por países exportadores agrícolas), demonstrando uma postura proativa desde então. Nessa ocasião, não apenas participaram do processo de negociação o Mapa, representando os interesses do agrobusiness, como também o Ministério do Desenvolvimento Agrário que, a partir do Decreto 5.453/2005, passou a fazer parte nos debates de comércio exterior via Camex, buscando se envolver nos assuntos referentes à proteção da agricultura familiar. Cabe ressaltar que a própria temática da agricultura no âmbito do G-20/OMC nunca foi resultado de um consenso de interesses, porque os países além de possuírem representações econômicas, geográficas, naturais e políticas diferentes, possuem perfis de agricultura também distintos, levando, inclusive, alguns membros a expressarem posições defensivas em função da relevância do seu segmento de subsistência.

O estopim dessas divergências internas da coalizão teve sua expressão máxima em 2008, quando o Brasil aceitou o pacote ofertado pela OMC em detrimento da resistência de alguns dos membros do grupo, tais com Índia, China e Argentina. Essa mudança da postura brasileira frente ao G-20, para Carvalho (2010), teria sido resultado da crescente influência dos grupos de interesses domésticos, capitaneados por representantes do agrobusiness (Ícone, CNA e Abag), que desde o início da Rodada de Doha, estariam levando suas demandas e dando suporte técnico para o Mapa e MRE nas negociações desse tema.

Enfim, o que se pode observar nessa terceira fase, através de exemplos e da reconstrução das alterações nas dinâmicas decisórias, é que, em consonância com a complexidade e abrangência adquirida na agenda comercial internacional, o número de órgãos do Executivo envolvidos com as negociações externas também cresceu, além do adensamento desse envolvimento e os impactos gerados no conteúdo das políticas.

\section{CONSIDERAÇÕES FINAIS}

Os resultados da pesquisa apontaram que as mudanças de ordem sistêmica (internacional e doméstica) que foram acentuadas a partir da década de 1990 exerceram impactos significativos no modus operandi da área de promoção comercial brasileira. Essas remodelagens 
institucionais em curso têm sido direcionadas para a constituição de espaços múltiplos de coordenação de preferências entre as estruturas burocráticas do Estado, demonstrando um esforço crescente também em ampliar os canais de diálogos entre os setores organizados da sociedade e o governo. Isso, porém, não significa dizer que essas estruturas estejam sólidas, tampouco que tenham resolvido a problemática de articulação burocrática, minimizando os conflitos e ampliando a coordenação dos resultados.

A própria Camex é um exemplo disso. Constituída sob a guarda da Presidência, mantinha um melhor status decisório, embora, operacionalmente, representasse um vetor de paralisia. Por outro lado, quando passou para o domínio do MDIC, resolveu a problemática da dinâmica decisória, mas perdeu poder e status junto a seus pares por deixar de ser um órgão supraministerial, submetendo-se ao jogo de disputas interburocráticas. Em 2016, a Camex foi vinculada novamente ao comando (Decreto 8.807/2016) da Presidência da República, sendo o Conselho da Camex, órgão de deliberação definitiva, presidida pelo Ministro-Chefe da Casa Civil. Esse redesenho demonstra uma nova alteração no arranjo institucional e decisório do principal órgão de apoio à promoção comercial e investimento e, sob os quais, seguem submetidos os seguintes órgãos: Conselho da Camex; Secretaria-Executiva; Conselho Consultivo do Setor Privado (Conex); Comitê de Financiamento e Garantia das Exportações (Cofig); Comitê Nacional de Facilitação de Comércio (Confac); e Comitê Nacional de Investimentos (Coninv). Portanto, o processo de maturação institucional que vem passando a Camex desde sua criação tem esbarrado em inúmeros desafios seja na execução da articulação horizontal, seja, entre os Ministérios envolvidos com essa área, seja verticalmente, isto é, entre o governo federal e a classe empresarial.

Outro redesenho recente realizado na estrutura de apoio ao comércio exterior foi no âmbito da Apex. O governo Michel Temer (2016), a pedido do então Ministro das Relações Exteriores, concedeu ao Itamaraty a presidência da Apex (Decreto 8.788/2016), retirando-o do domínio burocrático do Ministério de Desenvolvimento, Indústria e Comércio (Decreto 4.584/2003), enfraquecendo o poder decisório e a relevância institucional desse Ministério no âmbito da promoção comercial brasileira. Com isso, o que se pode observar é que essa área tem migrado entre as estruturas do Poder Executivo de forma muito recorrente, como num jogo de forças que se altera periodicamente, gerando certa 
confusão institucional e decisória, dificultando a consolidação da área e das ferramentas de apoio, assim como prejudicando a própria interação com o setor privado, que fica refém dessas nuances e dos impactos que isso representa para o conteúdo das políticas.

Ademais, sem nenhuma pretensão de esgotar o assunto, o estudo explorou, através de alguns exemplos, correlações entre as alterações na estrutura decisória da área e o impacto no resultado das políticas. com isso, foi possível observar que as dinâmicas interativas entre as burocracias começaram a impactar de forma crescente as rotinas de trabalho do Itamaraty, sobretudo, com a formação de grupos de trabalhos interministeriais para definição do posicionamento externo do Brasil nos foros multilaterais. Em outros termos, significa dizer que o órgão que estava acostumado até então a definir de maneira insulada os rumos das negociações, apenas fazendo consultas informais a determinados órgãos correspondentes, passa a ter que dialogar, interagir e, por vezes, disputar força com outras burocracias, como ocorreram nas reuniões preparatórias para as negociações da Rodada de Tóquio do GATT e também na própria formação do posicionamento brasileiro junto ao G-20/OMC no decorrer da Rodada de Doha.

Essa crescente horizontalidade das arenas decisórias indica um movimento para um fenômeno que se evidenciou caracterizar teoricamente de "modelo político burocrático" (Allison, 1971). Porém, cabe ressaltar, que para conclusões mais assertivas em relação a essa dinâmica decisória da área do comércio exterior serão necessários estudos de casos mais detalhados, que visem reconstruir a dinâmica do jogo, as forças correspondentes entre os principais atores envolvidos em uma negociação, de modo a se configurar um emaranhado de interesses em disputa, tal qual previsto no modelo. Assim também, essa trajetória de empoderamento político das burocracias no Brasil leva a necessidade de adensar pesquisas empíricas que explorem os mecanismos de controle democrático que o Estado tem sobre esses agentes.

Sendo assim, as remodelagens ocorridas nos arranjos institucionais e decisórios do setor de promoção comercial brasileiro também nos ofereceu uma base de reflexão sobre a inevitabilidade de abordar teoricamente temas relativos à política externa de forma integrada. Isso porque, como foi possível observar empiricamente, em grande medida, as transformações na dinâmica da gestão pública nessa área responderam às transformações de ordem sistêmica que vinham 
ocorrendo tanto no cenário internacional como doméstico, forçando as estruturas estatais a lidar com o envolvimento crescente de atores não governamentais nesse contexto. Isso envolve compreender a natureza contemporânea que o Estado vem adquirindo com características de atuação de rede, menos hierarquizada, e mais dinâmica, a fim de responder a processos cada vez mais abrangentes e multifatoriais.

(Recebido para publicação em 30 de janeiro de 2019) (Aprovado para publicação em 12 fevereiro de 2019)

\section{NOTAS}

1. Informações extraídas do site www.mdic.gov.br/arquivos/dwnl_1251143349.pdf. Acesso em 10/06/2016.

2. Em 2017 o portal passou a chamar-se Invest \& Export Brasil. Ver http:/ /www.investexportbrasil.gov.br/

3. Informações disponíveis em http:/ / www.apexbrasil.com.br/quem-somos. Acesso em 15/06/2016.

4. Grupo de países que representam $43 \%$ da população mundial, $30 \%$ da área territorial do globo e mais de $20 \%$ do Produto Interno Bruto (PIB) do mundo.

5. Informações extraídas de http://legislacao.planalto.gov.br/legisla/legislacao.nsf/ Viw_Identificacao/DEC\%204.418-2002?OpenDocument. Acesso em 12/06/2016

6. Informações extraídas do site http://www.planalto.gov.br/ccivil_03/_ato20042006/2004/decreto/D4993.htm. Acesso em 14/06/2016

7. Informações extraídas de http://www.itamaraty.gov.br/pt-BR/component/tags/ tag/390-promocao-comercial. Acesso em 24/04/2017. 


\section{REFERÊNCIAS BIBLIOGRÁFICAS}

ALLISON, Graham T.; Zelikow, Philip (1999). Essence of decision: Explaining the Cuban missile crisis (Vol. 2). New York: Longman.

ALLISON, Graham T. (1971), Essence of decision: explaining the cuban missile crisis. Boston: Little; Brown.

BARROS, Alexandre de S. C. (1986), “A formulação e a implementação da política externa brasileira: o Itamaraty e os novos atores". In: H. Muñoz e J. S. Tulchin (orgs.), A América Latina e a política mundial. São Paulo: Editora Convívio.

BEHN, Robert D. (1998), “O novo paradigma da gestão pública e a busca da accountability democrática". Revista do Serviço Público, ano 49, (4), out./dez., pp. 5-45.

CARLSNAES, Walter; GUZZINI, Stefano. (2011), "Historical overview". in: W. Carlsnaes and Stefano Guzzini (eds.), Foreign policy analysis. Los Angeles: Sage.

CARVALHO, Maria Isabel V. de. (2010), "Condicionantes internacionais e domésticos: o Brasil e o G-20 nas negociações agrícolas da Rodada Doha". DADOS, 53(2), pp. 405-445.

CASTELAN, Daniel R. (2009), O fim do consenso e o consenso do fim. A reforma da política comercial brasileira entre 1985 e 1994. Dissertação (Mestrado em Relações Internacionais), PUC-Rio, Rio de Janeiro.

. (2011), “A implementação do consenso: Itamaraty, Ministério da Fazenda e a liberalização brasileira". Contexto Internacional (PUCRJ. Impresso), vol. 32, pp. 563-605.

CUNHA, Raphael C. (2008), Preferências domésticas e diplomacia comercial: a posição negociadora brasileira sobre o comércio de serviços nas rodadas Uruguai e Doha. Dissertação (Mestrado em Relações Internacionais), Universidade de Brasília, Brasília.

DICKEN, Peter. (2007), Global shift: mapping the changing contours of the world economy. New York: The Guilford Press.

FARIAS, Rogério de Souza. (2007), O Brasil e o GATT (1973-1993): Unidades decisórias e política externa. Dissertação (Mestrado em Relações Internacionais), Universidade de Brasília, Brasília.

FERNANDES, Ivan Filipe de A. L. (2010), Burocracia e política: a construção institucional da política comercial brasileira pós-abertura econômica. Dissertação (Mestrado em Ciência Política), Universidade de São Paulo, São Paulo.

FERNANDES, Ivan Filipe A. L. (2013), "A construção institucional da política comercial brasileira: a câmara de comércio exterior (Camex) no governo Cardoso". Revista de Sociologia e Política. 21(45), pp. 123-148.

FIGUEIRA, Ariane C. R. (2009), Processo decisório em política externa no Brasil. Tese (Doutorado em Ciência Política), Universidade de São Paulo, São Paulo.

FREY, Klaus. (2000), "Políticas públicas: um debate conceitual e reflexões referentes à prática da análise de políticas públicas no Brasil”. Planejamento e Políticas Públicas, (21), pp. 211-259. 
HELD, David. (1991), "A Democracia, o Estado-Nação e o Sistema Global”. Lua Nova, (23), pp. 145-194.

HUDSON, Valerie M.; VORE, Christopher S. (1995), "Foreign policy analysis yesterday, today and tomorrow". Mershon International Studies Review, 39(2), pp. 209-238.

JESUS, Diego S. V. (2014), “A essência de uma subárea: os 60 anos da análise de política externa". Estudos Internacionais (PUC Minas), 2(1), pp. 81-99.

KEOHANE, Robert O.; NYE, Joseph S. (1998), "Power and interdependence in the information age". Foreign Affairs, 77(5), pp. 81-94.

LIMA, Maria Regina Soares de; SANTOS, Fabiano. (2001), “O congresso e a política de comércio exterior". Lua Nova, (52), pp. 121-149.

LOPES, Dawisson Belém. (2011), “A política externa brasileira e a 'circunstância democrática': do silêncio respeitoso à politização ruidosa". Revista Brasileira de Política Internacional, 54(1), pp. 67-86.

MANCUSO, Wagner P. M.; OLIVEIRA, Amâncio J. D. (2004), “Abertura econômica, empresariado e política no Brasil contemporâneo". Dados, 47, pp. 147-162.

MILANI, Carlos R. S.; PINHEIRO, Leticia. (2013), "Política externa brasileira: os desafios de sua caracterização como política pública". Contexto Internacional, 35(1), pp. 11-41.

NASSIF, André L. (1995), Política industrial e proteção no Brasil: o papel da Cacex. Dissertação (Mestrado em Economia), Universidade Federal Fluminense, Rio de Janeiro.

NEACK; HEY; HANEY. (1995), Foreign policy analysis: continuity and change in its second generation. Englewood Cliffs: Prentice Hall.

NISKANEN, William A. (1971), Bureaucracy and representative government. Chicago: Aldine Atherton.

OLIVEIRA, Ivan Tiago Machado; MILANI, Carlos R. S. (2012), “Atores não estatais e trade policy-making no Brasil: Análise dos Interesses e das Estratégias da CEB e da REBRIP". Dados, 55, pp. 367-401.

OLIVEIRA, Ivan Tiago Machado. (2013), A política comercial externa brasileira: uma análise de seus determinantes. São Paulo: Saraiva, vol. 1.

RAMOS, Guilherme C. (2008), Comércio internacional, política comercial brasileira e a atuação da câmara de comércio exterior (Camex) na condução das políticas para o setor. Dissertação (Mestrado em Gestão Pública), FGV, Rio de Janeiro.

ROSATI, Jerel A. (1981), “Developing a systematic decision-making framework: bureaucratic politics in perspective". World Politics, 33(2), pp. 234-252.

ROSENAU, James N. (1966), Pre-theories and theories of foreign policy. Evanston: Northwestern University Press.

SALOMÓN, Mónica; PINHEIRO, Letícia (2013), “Análise de política externa e política externa brasileira: trajetória, desafios e possibilidades". Revista Brasileira de Política Internacional, 56, pp. 40-59.

SANTANA, Helton R. P. (2001), "Grupos de interesse e a política externa brasileira para a ALCA". Contexto Internacional, 23(1), pp. 167-196. 


\section{Ariane Figueira}

SNYDER, Richard C. ; BRUCK, Henry W.; SAPIN, Burton. (1954), Decision-making as an approach to the study of international politics. Princeton: Princeton University Press.

SPROUT, Harold; SPROUT, Margaret. (1956), Man-milieu relationship hypotheses in the context of international politics. Princeton: Princeton University Press.

STOPFORD, John.; STRANGE, Susan. (1991), Rival states, rival firms: competition for world market shares. London: Cambridge University Press.

THORSTENSEN, Vera. (2001), OMC - Organização mundial do comércio: as regras do comércio internacional e a nova rodada de negociações multilaterais. São Paulo: Aduaneiras.

VEIGA, Pedro da Motta.; IGLESIAS, Roberto M. (2002), A institucionalidade da política brasileira de comércio exterior. Relatório preliminar. Fundação Centro de Estudos do Comércio Exterior.

VEIGA, Pedro da Motta. (2005), "Formulação de políticas comerciais no brasil: a mudança do padrão de relacionamento entre o estado e a sociedade civil". Revista Brasileira de Comércio Exterior, 86, pp. 1-35.

VICARI, Talita B. (2010), Governo eletrônico e promoção comercial: a influência da gestão do conhecimento na dinâmica exportadora de micro e pequenas empresas. Brasília: Fundação Alexandre Gusmão.

YIN, Robert. (1994), Case study research: design and methods. Newbury Park: Sage. 


\section{RESUMO \\ As Remodelagens Institucionais nas Estruturas de Apoio à Promoção Comercial no Brasil}

O objetivo do artigo é compreender como a administração pública brasileira vem respondendo, sob o ponto de vista dos arranjos institucionais e decisórios, às demandas crescentes na área de promoção comercial. O método utilizado foi o estudo de caso, que propicia uma visão aprofundada e longitudinal do processo. As fontes da pesquisa foram de natureza primária e secundária, sendo os dados tratados a partir das técnicas da triangulação e da análise de conteúdo. Os resultados encontrados revelaram que o histórico do processo organizacional e decisório de promoção comercial brasileira foi marcado por três fases: a primeira, referente à constituição e consolidação da área, verificadas dentro da estrutura organizacional do Itamaraty; a segunda, caracterizada pela perda de espaço na centralidade da formulação e decisão dessa política, resultando em uma fragmentação e dispersão de responsabilidades; e a terceira, pela crescente constituição de espaços formais de diálogo interburocrático e com o setor empresarial.

Palavras-chave: política externa; promoção comercial; arranjos institucionais; processo decisório; gestão pública

\section{ABSTRACT \\ Institutional Remodeling of the Support Structures for Commercial Promotion in Brazil}

The goal of this article is to understand how Brazilian public administration has been responding, from the point of view of institutional and decision-making arrangements, to the growing demands in the area of commercial promotion. In order to achieve this goal, we have chosen the case study method, which provides an in-depth and longitudinal view of the process. The sources of the research are of primary and secondary nature, and the data were treated using triangulation and content analysis techniques. The results showed that the history of the organizational and decision-making process of Brazilian commercial promotion was marked by three phases: the first, in which the area was constituted and consolidated, within Itamaraty's organizational structure; the second, characterized by the loss of space in the centrality of the formulation and decision of this policy, resulting in a fragmentation and dispersion of responsibilities; and the third, where there is a growing building of formal spaces of interbureaucratic dialogue, as well as with the business sector.

Keywords: foreign policy; commercial promotion; institutional arrangements; decision-making process; public administration 


\section{RÉSUMÉ \\ Le Remodelage Institutionnel des Structures d'Appui à la Promotion Commerciale au Brésil}

L'objectif de cet article est de comprendre comment l'administration publique brésilienne a réagi, vers la perspective des arrangements institutionnels et décisionnels, à l'augmentation des activités concernantes à la promotion commerciale. La méthode utilisée était l'étude de cas, qui fournit une vue en profondeur et longitudinale du processus. Les sources de la recherche étaient de nature primaire et secondaire et les données ont été traitées à l'aide de techniques de triangulation et d'analyse de contenu. Les résultats ont montré que l'histoire du processus organisationnel et décisionnel de la promotion commerciale brésilienne a été marquée par trois phases: la première, relationnée à la constitution et à la consolidation de la zone, vérifiée dans la structure organisationnelle d'Itamaraty; la seconde, caractérisée par la perte d'espace dans la centralité de la formulation et de la décision de cette politique, aboutant à une fragmentation et une dispersion des responsabilités; et la troisième, par la constitution croissante d'espaces formels de dialogue inter-bureaucratique et avec le secteur des affaires business.

Mots-clés: politique étrangère; promotion commerciale; arrangements institutionnels; processus décisionnel; gestion publique

\section{RESUMEN}

Las Remodelaciones Institucionales en las Estructuras de Apoyo a la Promoción Comercial en Brasil

El objetivo del artículo es comprender cómo la administración pública brasilera viene respondiendo, desde el punto de vista de los acuerdos institucionales y decisorios, a las crecientes demandas en el área de promoción comercial. El método utilizado fue el de estudio de caso, que propicia una visión profunda y longitudinal del proceso. Las fuentes de la investigación fueron de naturaleza primaria y secundaria, tratando los datos a partir de las técnicas de triangulación y de análisis de contenido. Los resultados encontrados revelaron que el histórico del proceso organizacional y de decisión de la promoción comercial brasilera fue marcado por tres fases: la primera, referente a la constitución y consolidación del área, verificadas dentro de la estructura organizacional del Itamaraty; la segunda, caracterizada por la pérdida de espacio en la centralidad de la formulación y decisión de esa política, resultando en una fragmentación y dispersión de responsabilidades; y la tercera, por la creciente constitución de espacios formales de diálogo interburocrático y con el sector empresarial.

Palabras clave: política exterior; promoción comercial; acuerdos institucionales; proceso de decisión; gestión pública 